\title{
A study on the correlation of clinical and ultrasonography diagnosis with histopathological outcome in cases of hysterectomy
}

\author{
Debapriya Saha ${ }^{1}$, Prince Parikh ${ }^{2 *}$, Nimesh Bharatkumar Thakkar ${ }^{3}$
}

\begin{abstract}
${ }^{1}$ Consultant Gynecologist, Apollo Hospitals International Ltd, Ahmedabad, Gujarat, India
${ }^{2}$ Consultant Gynecologist, Sub-District-Hospital Singarva, Ahmedabad, Gujarat, India

${ }^{3}$ Department of General Surgery GMERS Medical College, Gandhinagar, Gujarat, India
\end{abstract}

Received: 07 May 2020

Accepted: 30 May 2020

\author{
*Correspondence: \\ Dr. Prince Parikh, \\ E-mail: princeparikh97@gmail.com
}

Copyright: (c) the author(s), publisher and licensee Medip Academy. This is an open-access article distributed under the terms of the Creative Commons Attribution Non-Commercial License, which permits unrestricted non-commercial use, distribution, and reproduction in any medium, provided the original work is properly cited.

\begin{abstract}
Background: Hysterectomy is the most commonly performed gynaecological operation throughout the world due to different causes of pelvic pathology. Fewer studies have been performed describing the relationship between preoperative clinical, ultrasonological diagnosis and histopathological outcome.

Methods: Authors report 100 cases with benign gynecological disorders who underwent hysterectomy. Authors excluded malignant cases from the study. A preoperative diagnosis was formed based on clinical and ultrasound examination and it was compared with the histopathological report of the hysterectomy specimen.

Results: In this study the most common preoperative diagnosis for hysterectomy was fibroid uterus (39\%) among which $94.87 \%$ showed positive correlation with HPE. Correlation for adenomyosis was $100 \%$ between preoperative diagnosis and HPE outcome. Correlation for DUB was poor. 57.14\% of the preoperatively diagnosed DUB cases showed adenomyosis on HPE. One case of fibroid showed adenocarcinoma of endometrium on HPE.

Conclusions: The study fulfills the aim of finding the efficacy of clinical and USG findings in diagnosing gynecological disorders accurately. Clinical examination is not always adequate. USG is the most important, simple and easily accessible investigation. There is one missed malignant case in this study which is a major shortcoming of clinical evaluation.
\end{abstract}

Keywords: Adenomyosis, Dysfunctional uterine bleeding, Fibroid, Histopathology, Hysterectomy, Ultrasonography

\section{INTRODUCTION}

Hysterectomy is the commonest gynaecological surgery all over the world. ${ }^{1}$ Hysterectomy was first performed in 1507 by Berengarius of Bolonga through the vaginal route. But the credit for first vaginal hysterectomy was given to Langen, back in 1813. In November 1843, Charles Clay performed the first abdominal hysterectomy in Manchester, England. ${ }^{2}$ In 1929, Richardson, MD, performed the first total abdominal hysterectomy.

After caesarean delivery, hysterectomy is the most frequently performed major surgical procedure in the United States 18. In USA hysterectomy rate was found to be 5.38 per 1000 women. ${ }^{3}$ In India, a large-scale survey revealed hysterectomy prevalence of 17 per 1000 ever married women. The number of women undergoing hysterectomy ranged from 2 to 63 per 1000 ever married women across different states of India. ${ }^{4}$

The US centre for disease control and prevention (CDC) estimated 3.1 million US women had hysterectomy from 2000-2004. The rates were highest among women aged 40-44 years. ${ }^{5}$ However today, the number of hysterectomies conducted in India continues to outnumber surgeries performed in other countries. For instance, number of hysterectomies conducted in 2013 in India stood at 23.2 lakh, while during the same period 
hysterectomies reported in USA, UK and Russia were 5.9 lakh, 1.3 lakh and 3.12 lakh respectively. ${ }^{6}$

It has been observed in certain areas that between $21.4 \%$ and $44.7 \%$ of the submitted samples from hysterectomy reveal no pathology after histological evaluation and for some conditions the indication will not be justified and not worth the risk. ${ }^{7}$ Keeping this in mind, authors started the study to find out the efficacy of clinical and USG findings in diagnosing gynaecological disorders so that only valid indicated cases are taken up for hysterectomy.

\section{METHODS}

The study was conducted in a tertiary care hospital in Gujarat, India. A total 100 patients. One and half year (July 2018 to January 2020). It is a prospective, observational, analytical study. The study included the patients satisfying the inclusion criteria. Necessary information for the study was collected after taking informed written consent by a face to face interview, clinical examination of the patients, ultrasonography and then selected for hysterectomy and followed up for histopathological reports.

\section{Inclusion criteria}

- Patients with age group above 35 years with clinically diagnosed benign gynecological disorders requiring hysterectomy.

\section{Exclusion criteria}

- Patient with emergency hysterectomy for postpartum hemorrhage

- Already diagnosed malignant cases.

\section{Parameters to be studied}

- Demographic character of the sample- age

- Disease profile- presenting symptoms

- Preoperative clinical diagnosis based on history, clinical examination and USG findings

- HPE confirmation of preoperative clinical diagnosis and USG findings.

\section{Methodology}

Those patients who attended gynaecology OPD, detailed history was taken based on presenting symptoms and was examined clinically (per abdomen, per speculum, per vaginal, per rectal) and then followed by USG.

Symptomatic fibroid, adenomyosis, endometriosis, chronic pelvic pain, uterine prolapse and cases of heavy menstrual bleeding not responding to medical therapy were selected for hysterectomy. All cases were evaluated by routine blood investigations and $\mathrm{D}$ and $\mathrm{C}$ was done routinely for all cases post-menopausal bleeding before selecting for hysterectomy. Informed consent was taken and study Proforma was filled for each subject.

The gross (macroscopic) features of the specimen were noted and then specimens were immediately fixed with $10 \%$ formalin and sent to pathology department for microscopic evaluation.

\section{RESULTS}

In this study majority of patients were from age group of 41-50 years (58\%) followed by age group of 51-60 years (34\%) (Table 1).

Table 1: Age distribution of patients.

\begin{tabular}{|lll|}
\hline Age & Frequency & Percentage \\
\hline $41-50$ & 58 & $58.0 \%$ \\
\hline $51-60$ & 34 & $34.0 \%$ \\
\hline $61-70$ & 8 & $8.0 \%$ \\
\hline Total & 100 & $100.0 \%$ \\
\hline
\end{tabular}

The most common presenting complain was Heavy menstrual bleeding in $43 \%$ cases and the least common presenting complain was something coming out per vagina in $11 \%$ cases (Table 2 ).

Table 2: Presenting symptom of patients.

\begin{tabular}{|lll|}
\hline Presenting symptoms & Frequency & Percentage \\
\hline Dysmenorrhoea & 18 & $18.0 \%$ \\
\hline Heavy menstrual bleeding & 43 & $43.0 \%$ \\
\hline Pain abdomen & 11 & $11.0 \%$ \\
\hline Postmenopausal bleeding & 17 & $17.0 \%$ \\
\hline Something coming out P/V & 11 & $11.0 \%$ \\
\hline Total & 100 & $100.0 \%$ \\
\hline
\end{tabular}

Table 3: Ultrasonographic findings of the patients.

\begin{tabular}{|lll|}
\hline $\begin{array}{l}\text { Preoperative diagnosis } \\
\text { (clinical+USG) }\end{array}$ & Frequency & Percentage \\
\hline Adenomyosis & 9 & $9.0 \%$ \\
\hline Adnexal mass & 8 & $8.0 \%$ \\
\hline Chronic PID & 4 & $4.0 \%$ \\
\hline DUB & 28 & $28 \%$ \\
\hline Endometriosis & 1 & $1.0 \%$ \\
\hline Fibroid & 39 & $39.0 \%$ \\
\hline Uterine prolapse & 11 & $11.0 \%$ \\
\hline Total & 100 & $100.0 \%$ \\
\hline
\end{tabular}

In this study the commonest ultrasonographic finding was fibroid in 39\% patients and least common finding was adnexal mass in $8 \%$ patients. Normal ultrasonography finding was present in $31 \%$ case. $9 \%$ cases in this study was diagnosed as Adenomyosis by USG which showed features of globular enlarged uterus, heterogenous myometrial area, poor differentiation of endometrial and myometrial junction or discrete hypoechoic nodule or 
nodules with poorly defined margins (in contrast to fibroid where margin is clear). $13 \%$ of the patients were diagnosed to have Bulky uterus on USG (where uterus was enlarged in absence of any features of fibroid or adenomyosis) (Table 3 ).

The most common preoperative clinical diagnosis based on clinical findings and USG features was Fibroid (39\%) followed by DUB in $28 \%$ cases where no organic cause of uterine bleeding could be found by clinical examination and USG (Table 4).

Out of 100 specimens in the final histopathology report, leiomyoma was the most common finding reported in $44 \%$ followed by adenomyosis in $29 \%$ cases (Table 5). In this study the most common preoperative diagnosis for hysterectomy was Fibroid uterus (39\%) among which 94.87\% showed correlation with HPE (Table 5).

Table 5: Histopathological report of the patients.

\begin{tabular}{|lll|}
\hline HPE report & Frequency & Percentage \\
\hline Adenomyosis & 29 & $29.0 \%$ \\
\hline Atrophic endometrium & 10 & $10.0 \%$ \\
\hline Benign ovarian pathology & 5 & $5 \%$ \\
\hline Endometrial hyperplasia & 4 & $4.0 \%$ \\
\hline Leiomyoma & 44 & $44.0 \%$ \\
\hline $\begin{array}{l}\text { Adenocarcinoma } \\
\text { endometrium }\end{array}$ & 1 & $1.0 \%$ \\
\hline Normal & 7 & $7.0 \%$ \\
\hline Total & 100 & $100.0 \%$ \\
\hline
\end{tabular}

Table 6: Correlation between preoperative diagnosis and histopathology report.

\begin{tabular}{|c|c|c|c|}
\hline Preoperative diagnosis (clinical + USG) & HPE report & Total & Percentage \\
\hline \multirow{2}{*}{ Adenomyosis } & Adenomyosis & 9 & $100.00 \%$ \\
\hline & Adenomyosis total & 9 & \\
\hline \multirow{4}{*}{ Adnexal mass } & Benign ovarian pathology & 5 & $62.50 \%$ \\
\hline & Leiomyoma & 2 & $25.00 \%$ \\
\hline & Adenomyosis & 1 & $12.50 \%$ \\
\hline & Adnexal mass total & 8 & \\
\hline \multirow{5}{*}{ DUB } & Adenomyosis & 16 & $57.14 \%$ \\
\hline & Endometrial hyperplasia & 4 & $14.28 \%$ \\
\hline & Leiomyoma & 5 & $17.86 \%$ \\
\hline & Normal & 3 & $10.72 \%$ \\
\hline & DUB total & 28 & \\
\hline \multirow{3}{*}{ Chronic PID } & Atrophic endometrium & 1 & $25.00 \%$ \\
\hline & Normal & 3 & $75.00 \%$ \\
\hline & Chronic PID total & 4 & \\
\hline \multirow{2}{*}{ Endometriosis } & Benign ovarian pathology & 1 & $100 \%$ \\
\hline & Endometriosis total & 1 & \\
\hline \multirow{4}{*}{ Fibroid } & Adenomyosis & 1 & $2.56 \%$ \\
\hline & Leiomyoma & 37 & $94.87 \%$ \\
\hline & Endometrial Adenocarcinoma & 1 & $2.56 \%$ \\
\hline & Fibroid total & 39 & \\
\hline \multirow{4}{*}{ Uterine prolapse } & Adenomyosis & 1 & $9.09 \%$ \\
\hline & Atrophic endometrium & 9 & $81.82 \%$ \\
\hline & Normal & 1 & $9.09 \%$ \\
\hline & Uterine prolapse total & 11 & \\
\hline
\end{tabular}

Correlation for adenomyosis was $100 \%$. Correlation for DUB was poor. Out of 28 cases preoperatively diagnosed as DUB, on histopathology 16 cases (57.14\%) showed adenomyosis, 5 cases $(17.85 \%)$ showed leiomyoma and only 3 cases $(10.71 \%)$ showed normal histopathological findings. This can be possibly because most of the DUB cases were early evolving adenomyosis where uterine size was not significantly enlarged but presented with significant symptoms (Table 6).
Out of 11 cases of preoperative clinical diagnosis of uterine prolapse, 9 cases $(81.82 \%)$ showed atrophic endometrium. In this study, 1 case of fibroid showed adenocarcinoma of the endometrium $(2.56 \%)$ on HPE. Out of 8 cases preoperatively diagnosed as Adnexal mass, 5 cases $(62.5 \%)$ showed benign ovarian pathology like serous cyst, chocolate cyst, etc. 2 cases (25\%) showed leiomyoma on histopathology and 1 case $(12.5 \%)$ showed adenomyosis (Table 6). 
A total $25 \%$ showed leiomyoma because among preoperatively diagnosed adnexal masses authors found 1 case of broad ligament fibroid and 1 case of lateral wall fibroid to which adnexa was densely adhered, possibly due to which ultrasonologically it seemed to be adnexal mass (Table 6).

\section{DISCUSSION}

\section{Age of the patients}

In this study highest incidence of cases $(58 \%)$ was of age group 41-50 years, which is the most common age group for contracting diseases. In his study Subrata et al, observed average age of hysterectomy was 45.78 years. ${ }^{8}$ Highest percentage of patients was among 40-49 years $(48.31 \%)$ (Table 1).

\section{Presenting symptom}

In the study the major presenting symptom was heavy menstrual bleeding in 43 women out of 100 cases (43\%). 18 cases $(18 \%)$ presented with dysmenorrhea. $11 \%$ cases presented with pain abdomen irrespective of menstrual cycle. $17 \%$ of the cases presented with post-menopausal bleeding and $11 \%$ cases had the presenting symptom of something coming down per vagina. So, the least common presenting symptom in my study was something coming out per vagina, i.e., uterovaginal prolapse $(11 \%$ cases) (Table 2). Arti et al, found the commonest presenting symptom in the study population as menorrhagia, dysmenorrhea and other menstrual problems $(62 \%){ }^{9}$

\section{Ultrasonography findings}

Fibroid was the most common USG finding present in 39 out of 100 cases (39\%). $31 \%$ of the cases showed normal study in USG. This was followed by Bulky uterus in $13 \%$ of the cases, adenomyosis in $9 \%$ and adnexal mass in $8 \%$ of the cases (Table 3). Alakananda et al, found in ultrasonography, fibroid was the most common findings reported in $62 \%$ cases followed by bulky uterus in $17 \%$, adenomyosis in $13 \%$, adnexal mass in $1 \%$ and endometrial polyp in $1 \%$ of cases. Normal scan in $6 \%$ of cases were found. ${ }^{10}$

\section{Preoperative diagnosis (clinical + USG)}

The most common preoperative diagnosis was fibroid (39\%) and thus is the commonest indication of hysterectomy in this study set up. This was followed by DUB (28\%). Uterine prolapse is the third most common indication of hysterectomy in this study setup (11\%). Adenomyosis constituted $9 \%$ of the preoperative clinical diagnosis. Other less common preoperative indications include adnexal mass (8\%), chronic PID (4\%) and endometriosis (1\%) (Table 4). This study findings corroborates with most other studies. In a study by Rabiu and Habib in Nigeria, the most common indication of hysterectomy was uterine fibroid $(51.8 \%) .{ }^{11}$

\section{HPE report}

The gross macroscopic features of all the specimens of hysterectomy were noted and immediately fixed with $10 \%$ formalin were sent to the pathology department of study hospital for detailed microscopic examination. In specimens having multiple pathologies, the major pathology was charted in the master chart after discussion with the pathologist.

The most common HPE finding in my study was Leiomyoma (44\%) followed by Adenomyosis (29\%). Similar results were obtained by Karthiketan et al, where leiomyoma was $41 \%$ followed by adenomyosis which was $15.5 \% .^{12}$

In this study, $10 \%$ of the cases showed atrophic endometrium and 7 out of 100 cases (7\%) showed Normal HPE findings. This is probably associated with evaluation of each and every hysterectomy sample regardless of physical appearance and suspected diagnosis. Other diagnosis like dysfunctional uterine bleeding and pelvic organ prolapse might not have any histopathological finding detected (Table 5).

\section{Correlation between preoperative diagnosis (clinical+USG) with $\mathrm{HPE}$ report}

This correlation between preoperative diagnosis and HPE report is the major aim of this study as it will reflect the overall efficacy of this preoperative clinical diagnosis with postoperative HPE findings.

In this study the most common preoperative diagnosis for hysterectomy was fibroid uterus (39\%) among which $94.87 \%$ showed positive correlation with HPE. Correlation of preoperative diagnosis with postoperative histopathological outcome for adenomyosis was $100 \%$ (Table 6).

Correlation for DUB was poor. Out of 28 cases preoperatively diagnosed as DUB, on histopathology 16 cases $(57.14 \%)$ showed adenomyosis, 5 cases $(17.85 \%)$ showed leiomyoma and only 3 cases $(10.71 \%)$ showed normal histopathological findings. This can be possibly because most of the DUB cases were early evolving adenomyosis where uterine size was not significantly enlarged but presented with significant symptoms. Out of 11 cases of preoperative clinical diagnosis of Uterine prolapse, 9 cases $(81.82 \%)$ showed atrophic endometrium (Table 6).

In this study, 1 case of fibroid showed adenocarcinoma of the endometrium $(2.56 \%)$ on HPE. Out of 8 cases preoperatively diagnosed as adnexal mass, 5 cases $(62.5 \%)$ showed benign ovarian pathology like serous cyst, chocolate cyst, etc. 2 cases $(25 \%)$ showed 
leiomyoma on histopathology and 1 case (12.5\%) showed adenomyosis. 25\% showed leiomyoma because among preoperatively diagnosed adnexal masses authors found 1 case of broad ligament fibroid and 1 case of lateral wall fibroid to which adnexa was densely adhered, possibly due to which ultrasonologically it seemed to be adnexal mass (Table 6).

\section{CONCLUSION}

USG is an important, simple and easily accessible investigation to evaluate various causes of Acute uterine bleeding. Clinical examination is not adequate to distinguish between fibroid and adenomyosis. Transvaginal sonography should be used to distinguish fibroid and adenomyosis. Thus, preoperative diagnosis on the basis of clinical and USG findings may not always tally with histopathology, which is the ultimate diagnosis. Regarding correlation of clinical, USG and histopathology findings results were different for fibroid, DUB, uterine prolapse and adenomyosis.

In case of fibroid correlation of clinical and USG findings with histopathology was significant. In case of adenomyosis, correlation of USG finding with histopathology had markedly significant specificity. Though the very early evolving adenomyosis may be missed by USG, but transvaginal ultrasound had high specificity in diagnosing adenomyosis. In case of DUB correlation of clinical findings with USG and histopathology was poor. So, DUB patients should be judiciously managed and planned for hysterectomy. This may prevent inadvertent hysterectomy considering its own surgical risk and postoperative morbidity. Higher degree of suspicion and better diagnostic modality may prevent any missed malignant case.

Funding: No funding sources

Conflict of interest: None declared

Ethical approval: The study was approved by the Institutional Ethics Committee

\section{REFERENCES}

1. Vessey MP, Villard-Mackintosh LA, Mcpherson K, Coulter A, Yeates D. The epidemiology of hysterectomy: findings in a large cohort study. Int $\mathbf{J}$ Obstet Gynaecol. 1992;99(5):402-7.

2. John A, Rock MD, Jhon D, Thompson MD. Telinds's operative gynaecology. $1^{\text {st }}$ Edition Lippincott. Med J. 2003:878-890.
3. Wu JM, Wechter ME, Geller EJ, Nguyen TV, Visco AG. Hysterectomy rates in the United States, 2003. Obstet Gynecol. 2007;110(5):1091-5.

4. Prusty RK, Choithani C, Gupta SD. Predictors of hysterectomy among married women 15-49 years in India. Reprod Health. 2018;15(1):3.

5. Gor HB. Hysterectomy: Background, History of the procedure, problem; 2018, Available at: https://emedicine.medscape.com/article/267273overview. Accessed on $20^{\text {th }}$ February 2020.

6. Save the uterus seminar, 2014. Find it on indianewsreel.com Available at: http://www.indianewsreel.com/Health/Events/20141 523091527/Save-the-uterus-seminar.aspx. Accessed on $20^{\text {th }}$ February 2020.

7. Sobande AA, Eskander M, Archibong EI, Damole IO. Elective hysterectomy: a clinicopathogical review from Abha catchment area of Saudi Arabia. West African J Med. 2005;24(1):31-5.

8. Subrata P, Srabani C, Anuradha S, Prakash PJ, Kingshuk B, Mrinal S. A retrospective clinicopathological study of hysterectomy cases in a tertiary care hospital in India-a review of 950 cases. Bangladesh J Med Sci. 2018;17(1):88-92.

9. Kumari A, Biswas PK. Clinical and USG diagnosis versus histopathological outcome in cases of hysterectomy. Sch J App Med Sci. 2017;5(10D):4080-7.

10. Alakananda, Das KK, Muralidhara. A study on correlation of clinical and ultrasound diagnosis with histopathology in cases of hysterectomy done for benign indications. Int J Sci Res. 2017;6(11):755-8.

11. Rabiu A, Habib R. Elective abdominal hysterectomy: appraisal of indications and complications at Aminu Kano Teaching Hospital: an 8 year review. Trop J Obstet Gynaecol. 2017;34(3):224-8.

12. Karthikeyan TM, Veenaa NN, Ajeeth Kumar CR, Thomas E. Clinicopathological study of hysterectomy among rural patients in a tertiary care center. J Dent Med Sci. 2015;14(5):25-7.

Cite this article as: Saha D, Parikh $\mathrm{P}$, Thakkar NB. A study on the correlation of clinical and ultrasonography diagnosis with histopathological outcome in cases of hysterectomy. Int J Reprod Contracept Obstet Gynecol 2020;9:2921-5. 